\title{
Influência da incorporação de resíduo de escória de fluxo de soldagem nas propriedades tecnológicas de argamassa de múltiplo uso e cerâmica vermelha para construção civil
}

\section{(Influence of the incorporation of waste of slag of welding flux on the technological properties of multiple use mortar and red ceramic for civil construction)}

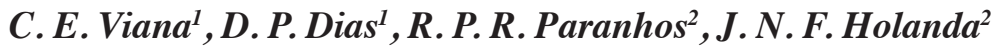 \\ ${ }^{1}$ Laboratório de Engenharia Civil, ${ }^{2}$ Laboratório de Materiais Avançados \\ Universidade Estadual do Norte Fluminense - UENF, Av. Alberto Lamego 2000 \\ Campos dos Goytacazes, RJ 28013-602 \\ carolineespinosa@gmail.com,dylmar@uenf.br,paranhos@uenf.br, holanda@uenf.br
}

\begin{abstract}
Resumo
O processo de soldagem a arco submerso é empregado em grande escala na indústria metal-mecânica. No entanto, este processo gera enorme quantidade de resíduo de escória. Em geral, este resíduo vem sendo disposto em lixões. Nos últimos anos, a área de cerâmica tem atraído grande atenção para reciclagem de resíduos industriais. Neste trabalho foi feito um estudo objetivando avaliar a influência do resíduo de escória de fluxo de soldagem sobre as propriedades tecnológicas de argamassa de múltiplo uso e cerâmica vermelha para uso na construção civil. O resíduo de escória de fluxo de soldagem foi caracterizado em relação à composição química, difração de raios X, análise do tamanho de partículas e massa específica real. A argamassa foi preparada com a incorporação de resíduo de escória de soldagem em substituição total de areia natural (agregado miúdo tradicional). As argamassas foram caracterizadas em termos de consistência, densidade de massa no estado fresco, teor de ar incorporado e resistência à compressão. Análise microestrutural das argamassas foi feita via MEV. Foi preparada também uma série de misturas argila/resíduo contendo até $10 \%$ em peso de resíduo de escória de fluxo de soldagem. As peças cerâmicas foram preparadas por prensagem uniaxial e queimadas entre $850{ }^{\circ} \mathrm{C}$ e $950^{\circ} \mathrm{C}$. As peças queimadas foram caracterizadas quanto à retração linear, absorção de água, porosidade aparente, massa específica aparente e tensão de ruptura à flexão. Os resultados mostraram que o resíduo de escória de fluxo de soldagem pode substituir areia natural como agregado miúdo em argamassa de múltiplo uso. Além do mais, o resíduo de escória pode ser incorporado em cerâmica vermelha (tijolos e blocos cerâmicos) como substituto parcial de argila natural.
\end{abstract}

Palavras-chave: escória de luxo de soldagem, resíduo, reciclagem, argamassa, cerâmica vermelha.

\begin{abstract}
The submerged-arc welding process is widely used in the metal-mechanic industry. However, this process generates huge amounts of slag waste. In general, this waste has been disposal in private waste deposits. In recent years, the ceramic area has attracted great attention for recycling of industrial wastes. In this work a study was done aiming evaluate the influence of the welding flux slag waste on the technological properties of multiple use mortar and red ceramics for use in civil construction. The waste sample was characterized regarding to chemical composition, X-ray diffraction, particle size analysis, and real density. The mortar was incorporated with welding flux slag waste in total substitution of natural sand (traditional small aggregate). The prepared mortars were characterized regarding to consistency, fresh state density, incorporated air content, and compressive strength. Microstructural analysis of the mortars was done via SEM. In addition, a series of clay/waste mixtures also was prepared with up to $10 \mathrm{wt} . \%$ of welding flux slag waste. The ceramic pieces were prepared by uniaxial pressing and fired between $850{ }^{\circ} \mathrm{C}$ and $950{ }^{\circ} \mathrm{C}$. The following technological properties after firing were determined: linear shrinkage, water absorption, apparent porosity, apparent specific mass, and flexural strength. The results show that the welding flux slag waste could replace the natural sand as small aggregate in multiple use mortar. In addition, the welding flux slag waste also could be incorporated into red ceramics (bricks and ceramic blocks) as partial replacement of natural red clay.
\end{abstract}

Keywords: welding flux slag, waste, recycling, mortar, red ceramic.

\section{INTRODUÇÃO}

O processo de soldagem a arco submerso é largamente empregado na indústria metal-mecânica devido a sua facilidade de operação e produtividade. No Brasil, este processo é usado na fabricação metálica como tubos, vasos de pressão, caldeiras e trocadores de calor, equipamentos siderúrgicos, navios, autopeças e todo tipo de equipamento pesado [1]. No processo de soldagem a arco submerso o calor para soldagem é fornecido por um arco elétrico formado 
entre um eletrodo de arame sólido ou tubular e a peça-obra. $\mathrm{O}$ arco elétrico fica completamente coberto por um fluxo que o protegerá, assim como o metal fundido e a poça de fusão da contaminação atmosférica. O fluxo granulado fundese parcialmente, formando uma camada de escória líquida que depois se solidifica. Este material sólido é considerado como sendo um resíduo sólido, que daqui por diante será denominado de resíduo de escória de fluxo de soldagem [2].

No Brasil a quantidade estimada de resíduo de escória de fluxo de soldagem gerada é de cerca de 750 ton/mês, sendo que $75 \%$ desse volume concentram-se no eixo Rio de Janeiro, São Paulo e Minas Gerais. No entanto, não existem no Brasil recomendações para reaproveitamento desse abundante resíduo. De forma que este resíduo, na maioria das vezes, tem sido disposto inadequadamente em lixões particulares. Por outro lado, este tipo de descarte eleva os custos das empresas com transporte e taxas para uso dos lixões. Nota-se que há grande interesse das indústrias do setor metal-mecânico em encontrar aplicação tecnológica para o resíduo de escória de fluxo de soldagem de forma ambientalmente limpa.

Materiais cerâmicos para uso na construção civil vêm sendo ao longo do tempo largamente pesquisado para incorporação de resíduos industriais diversos [3-5]. Entre os produtos cerâmicos que se destacam estão incluídos as argamassas de revestimento de paredes e tetos de casas e edifícios [6,7] e cerâmica vermelha [8-10]. Argamassas e produtos de cerâmica vermelha estão incluídos no grupo de materiais mais consumidos pelo Homem, que utilizam enormes quantidades de matérias-primas naturais. Ressaltase também que escórias metalúrgicas em geral têm sido estudadas como uma matéria-prima promissora na produção de materiais cerâmicos [7, 11-15].

Um dos tipos de argamassas mais empregadas na construção civil são as argamassas de múltiplo uso. Este tipo de argamassa pode ser empregada em assentamento de alvenaria de vedação, revestimentos de paredes e tetos e, ainda, para revestimento de pisos e contra-pisos. As argamassas são geralmente preparadas utilizandose areia natural. Isto tem conduzido a uma situação de grande preocupação com a extração desta matéria-prima natural não renovável [16]. Este problema tem aumentado principalmente ao redor das grandes cidades. No município de S. Paulo, por exemplo, a areia natural utilizada é captada em jazidas distantes a pelo menos $100 \mathrm{~km}$. Isto resulta em um aumento do custo em cerca de $300 \%$ em relação ao preço normal da areia [17]. Por outro lado, no processo produtivo da cerâmica vermelha são basicamente utilizadas argilas vermelhas naturais [18].

Neste trabalho o objetivo principal é estudar a influência do resíduo de escória de fluxo de soldagem sobre as propriedades tecnológicas de argamassa de múltiplo uso e cerâmica vermelha para uso na construção civil.

\section{MATERIAIS E MÉTODOS}

As matérias-primas usadas neste trabalho foram os componentes convencionais para fabricação de argamassa de múltiplo uso (cimento, areia natural e água) e tijolos e blocos cerâmicos (argila vermelha), além de resíduo de escória de fluxo de soldagem. Cimento Portland comercial (tipo CPIIE-32, Votoran) foi usado na preparação das argamassas. Este tipo de cimento foi escolhido por ser de fácil disponibilidade e, também, por ser largamente usado na produção de elementos construtivos não estruturais. Areia natural oriunda de rio, lavada e secada em estufa durante $24 \mathrm{~h}$, foi peneirada de modo a ser usada como areia normal segundo a NBR 7214 [19]. Do ponto de vista químico, a areia é composta basicamente por $\mathrm{SiO}_{2}$. A areia foi caracterizada em termos de massa específica aparente no estado solto [20] e massa específica real [21]. A amostra de argila sedimentar utilizada neste trabalho foi coletada de uma empresa do Pólo Cerâmico de Campos dos Goytacazes-RJ, a qual é normalmente usada na fabricação de tijolos e blocos cerâmicos para construção civil. A argila coletada na forma de torrões foi cominuída e submetida a peneiramento para fração $<40$ mesh. A argila sedimentar da região de Campos dos Goytacazes-RJ é predominantemente caulinítica [22]. A composição química da argila vermelha é dada na Tabela I.

A amostra de resíduo de escória de fluxo de soldagem utilizada foi coletada em indústrias do setor metal-mecânico localizadas no Estado de S. Paulo. A combinação arame/ fluxo que gerou essa escória é classificada pela norma AWS A5.17 como F7AO-EL12, como sendo fluxo do tipo ácido. A amostra de resíduo de escória de fluxo de soldagem coletada na forma in natura (cacos) foi submetida a processo de cominuição para produção de pó. A Fig. 1 apresenta o resíduo de escória de fluxo de soldagem. Para uso em argamassa o resíduo foi cominuído em um britador de rolo, visando a sua adequação de tamanho de partícula ao de um agregado miúdo natural. Já para uso em cerâmica vermelha, o resíduo foi cominuído e peneirado para a fração $<100$ mesh.

Análise por difração de raios $\mathrm{X}$ da amostra de resíduo foi feita com radiação Cu-k $\alpha$ (difratômetro Siemens D5000) em $40 \mathrm{kV}$ e $110 \mathrm{~mA}$. A composição química do resíduo foi

Tabela I - Composição química da argila vermelha (\%).

[Table I - Chemical composition of the red clay (\%).]

\begin{tabular}{cccccccccc}
\hline $\mathrm{SiO}_{2}$ & $\mathrm{Al}_{2} \mathrm{O}_{3}$ & $\mathrm{Fe}_{2} \mathrm{O}_{3}$ & $\mathrm{CaO}$ & $\mathrm{MgO}$ & $\mathrm{MnO}$ & $\mathrm{TiO}_{2}$ & $\mathrm{Na}_{2} \mathrm{O}$ & $\mathrm{K}_{2} \mathrm{O}$ & $\mathrm{PF}$ \\
\hline 46,42 & 27,90 & 9,10 & 0,22 & 0,71 & 0,11 & 1,32 & 0,36 & 1,67 & 11,96 \\
\hline PF = perda ao fogo
\end{tabular}




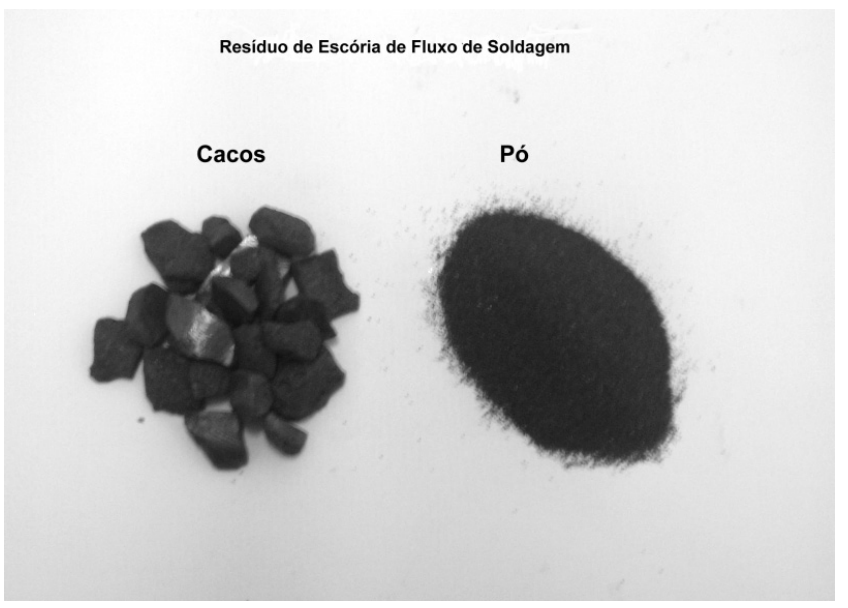

Figura 1: Amostra do resíduo de escória de fluxo de soldagem. [Figure 1: Welding flux slag waste sample.]

determinada por fluorescência de raios X. O ensaio de perda ao fogo foi feito a $1000{ }^{\circ} \mathrm{C}$. Além disso, a massa específica unitária do agregado no estado solto [20] e massa específica por meio do frasco de Chapman [23] foram determinadas.

Duas amostras de argamassas foram formuladas: argamassa formulada com agregado miúdo convencional (areia natural) e argamassa incorporada com resíduo de escória de fluxo de soldagem como agregado miúdo. As argamassas foram preparadas usando um misturador convencional de capacidade de $5 \mathrm{~L}$. O traço usado foi de 1:3 (relação cimento: agregado miúdo). A relação água:cimento foi determinada por meio do ensaio de consistência padrão [24]. As argamassas foram caracterizadas em termos de densidade de massa no estado fresco [25], teor de ar incorporado [25], teor de água e índice de consistência padrão [24]. A resistência à compressão das argamassas foi determinada de acordo com a norma NBR 13279 [26]. Os corpos-de-prova cilíndricos $(5 \mathrm{~cm}$ x $10 \mathrm{~cm})$ preparados foram submetidos à ruptura por compressão simples numa prensa hidráulica (Versa Tester) com taxa de carregamento de 0,5 MPa/s. Os corpos-de-prova foram rompidos para as seguintes idades: $0,1,3,7,28,90$ e 120 dias. Neste trabalho foram formuladas três massas de cerâmica vermelha contendo adições até $10 \%$ em peso de resíduo de escória de fluxo de soldagem: 1) massa cerâmica de referência denominada de MR0 (100\% de argila); 2) MR5 (95\% argila/5\% resíduo); e 3) MR10 (90\% argila/10\% resíduo). Os pós de argila e resíduo nas proporções pré-determinadas foram misturados e homogeneizados a seco utilizando-se um misturador cilíndrico de laboratório. As massas cerâmicas preparadas após secagem em $110{ }^{\circ} \mathrm{C}$ durante $24 \mathrm{~h}$ foram umidificadas para 7\% (massa de umidade/massa seca). Em seguida foram colocadas em sacos plásticos fechados e armazenadas em dessecador por $24 \mathrm{~h}$, para proporcionar homogeneização da umidade em toda massa de pó. A plasticidade das massas cerâmicas foi determinada pelo método de Atterberg de acordo com as normas NBR 6459-84 [27] e NBR 7180-84 [28].

Peças de cerâmica vermelha foram preparadas por prensagem uniaxial a $24 \mathrm{MPa}$ usando uma matriz de aço retangular $(11,5 \mathrm{~cm} \times 2,54 \mathrm{~cm})$. Em seguida as peças cerâmicas preparadas foram submetidas à secagem a 110 ${ }^{\circ} \mathrm{C}$ durante $24 \mathrm{~h}$. As peças cerâmicas devidamente secas foram queimadas em forno elétrico Câmara (Brasimet $\mathrm{K} 150$ ). As temperaturas de patamar foram $850{ }^{\circ} \mathrm{C}, 900$ ${ }^{\circ} \mathrm{C}$ e $950{ }^{\circ} \mathrm{C}$, com as peças mantidas por $2 \mathrm{~h}$. As seguintes propriedades tecnológicas das peças cerâmicas queimadas foram determinadas usando procedimentos padronizados: retração linear, absorção de água, porosidade aparente, massa específica aparente e tensão de ruptura a flexão.

\section{RESULTADOS E DISCUSSÃO}

O difratograma de raios $\mathrm{X}$ da amostra de resíduo de escória de fluxo de soldagem estudado é mostrado na Fig. 2. O resíduo de escória de fluxo de soldagem apresenta uma composição mineralógica complexa. Além da presença de fase amorfa, é possível se observar picos de difração característicos das fases cristalinas referentes à espinela $\left(\mathrm{MgAl}_{2} \mathrm{O}_{4}\right)$, sílica $\left(\mathrm{SiO}_{2}\right)$, espinela férrica $\left(\mathrm{Mg}(\mathrm{Al}, \mathrm{Fe})_{2} \mathrm{O}_{4}\right.$, rutilo $\left(\mathrm{TiO}_{2}\right)$, óxido de manganês $\left(\mathrm{MnO}_{2}\right)$, fluorita $\left(\mathrm{CaF}_{2}\right)$ e

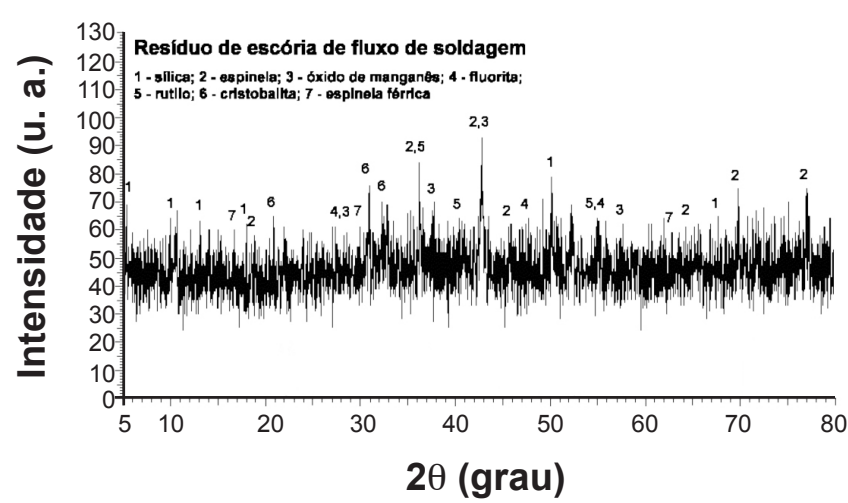

Figura 2: Difratograma de raios $\mathrm{X}$ do resíduo de escória do fluxo de soldagem.

[Figure 2: XRD pattern of the welding flux slag waste.]

cristobalita.

A composição química do resíduo de escória de fluxo de soldagem é apresentada na Tabela II. Do ponto de vista químico, o resíduo é constituído principalmente por $\mathrm{SiO}_{2}$, $\mathrm{Al}_{2} \mathrm{O}_{3}, \mathrm{MnO}_{2}$ e $\mathrm{TiO}_{2}$, que caracteriza o fluxo como sendo do tipo ácido [29]. O resíduo contém ainda quantidades razoáveis de $\mathrm{CaO}$ e $\mathrm{Fe}_{2} \mathrm{O}_{3}$, que são muito importantes nas formulações cerâmicas, pois auxiliam o processo de

Tabela II - Composição química do resíduo (\% em peso). [Table II - Chemical composition of the waste sample (wt.\%).]

\begin{tabular}{cccccccc}
\hline $\mathrm{SiO}_{2}$ & $\mathrm{Al}_{2} \mathrm{O}_{3}$ & $\mathrm{CaO}$ & $\mathrm{TiO}_{2}$ & $\mathrm{MnO}_{2}$ & $\mathrm{Fe}_{2} \mathrm{O}_{3}$ & $\mathrm{ZrO}_{2}$ & $\mathrm{PF}$ \\
\hline 20,84 & 27,39 & 5,01 & 10,02 & 25,80 & 6,72 & 2,84 & $2 *$ \\
\hline
\end{tabular}

*Ganho de peso 
sinterização. No experimento de perda ao fogo a $1000{ }^{\circ} \mathrm{C}$ foi constatado que a amostra de resíduo ganhou cerca de $2 \%$ em peso. Isto se deve provavelmente a oxidação de elementos como Mn sob atmosfera de ar.

A distribuição de tamanho de partícula do resíduo de escória de fluxo de soldagem é apresentada na Fig. 3. Nesta figura são apresentadas duas curvas granulométricas relacionadas ao uso do resíduo em argamassa e cerâmica vermelha. Na curva 1 tem-se a distribuição de tamanho de partícula do resíduo para uso em argamassa. Verifica-se que praticamente todo material cominuído passa na peneira de diâmetro nominal de $4,8 \mathrm{~mm}$. Isto indica que o resíduo de escória de fluxo de soldagem cominuído apresenta as dimensões de um agregado miúdo. Na curva 2 tem-se a distribuição de tamanho de partícula do pó de resíduo para uso em cerâmica vermelha. Pode-se observar que o resíduo apresenta larga distribuição de tamanho de partícula, sendo que o tamanho médio de partícula corresponde a cerca de $70 \mu \mathrm{m}$. Os resultados de tamanho de partícula do resíduo (curva 2) quando comparados com aqueles de algumas escalas internacionais para classificação de solos para construção civil [18] tem-se que: teor de fração argila $(<2$ $\mu \mathrm{m})$ de $3,1 \%$, teor de silte $(2 \leq \mathrm{x}<63 \mu \mathrm{m})$ de $39,9 \%$ e teor de areia fina $(63 \leq x<200 \mu \mathrm{m})$ de $57 \%$.

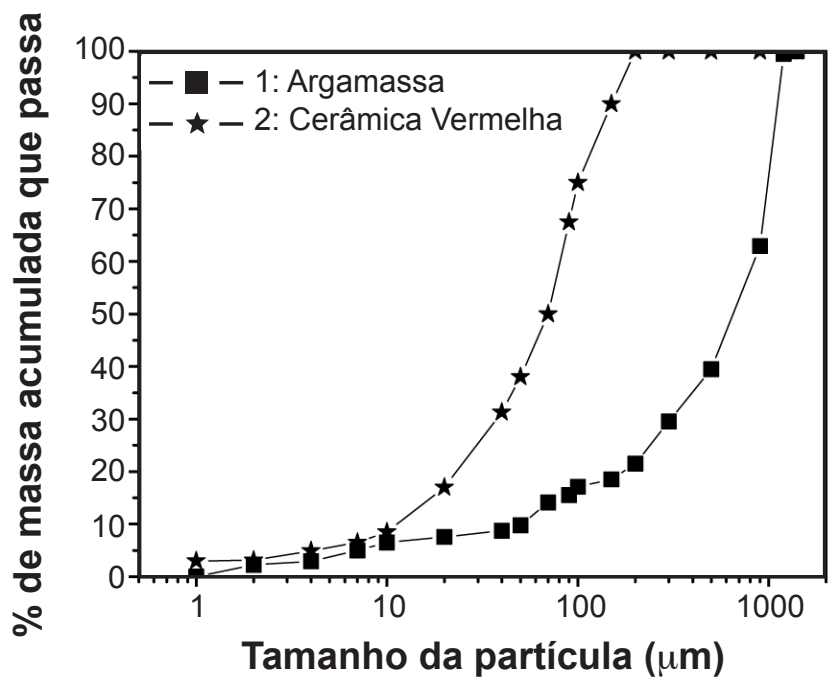

Figura 3: Distribuição de tamanho de partícula do resíduo de escória de fluxo de soldagem.

[Figure 3: Particle size distribution of welding flux slag waste.]

A Fig. 4 apresenta a plasticidade para as massas de cerâmica vermelha. Fica evidente que o efeito do resíduo de escória de fluxo de soldagem é o de reduzir gradualmente o índice de plasticidade da argila vermelha pura. Isto significa que o resíduo de escória de fluxo de soldagem atua como um redutor de plasticidade. Com efeito, os experimentos realizados na amostra de resíduo de escória de fluxo de soldagem indicaram que o mesmo é um material não plástico. Verifica-se, no entanto, todas as massas cerâmicas apresentaram plasticidade dentro da faixa adequada para fabricação industrial de cerâmica

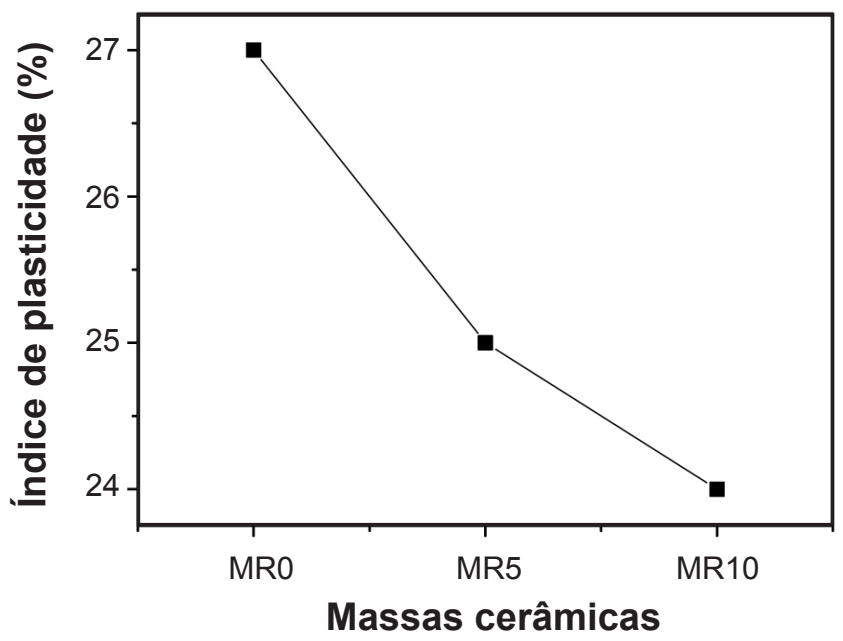

Figura 4: Plasticidade das massas cerâmicas.

[Figure 4: Plasticity of the ceramic pastes.]

Tabela III - Massa específica unitária e massa específica real das amostras.

[Table III - Unitary specific mass and real specific mass of the samples.]

\begin{tabular}{ccc}
\hline Amostras & $\begin{array}{c}\text { Massa específica } \\
\text { unitária }\left(\mathrm{g} / \mathrm{cm}^{3}\right)\end{array}$ & $\begin{array}{c}\text { Massa específica } \\
\text { real }\left(\mathrm{g} / \mathrm{cm}^{3}\right)\end{array}$ \\
\hline Areia natural & 1,39 & 2,62 \\
Resíduo de EFS & 2,65 & 3,38 \\
\hline
\end{tabular}

vermelha [30].

A Tabela III apresenta os resultados de massa unitária de agregado no estado solto e massa específica real para a areia natural (agregado tradicional) e resíduo de escória de fluxo de soldagem. Os resultados mostram que o resíduo de escória de fluxo de soldagem é mais denso do que a areia usada como material agregado natural.

Os resultados de consistência e o conteúdo de água das argamassas preparadas são apresentados na Tabela IV. Observa-se que o teor de água das argamassas é muito similar, independentemente do tipo de agregado miúdo. O índice de consistência padrão é um parâmetro normalmente utilizado para caracterizar argamassas, onde é estabelecido que a argamassa deva apresentar consistência de $255 \pm 10 \mathrm{~mm}$ medida na mesa de abatimento [24]. Os resultados demonstram que as argamassas apresentaram consistência dentro da faixa recomendada. De forma que a substituição de areia natural

Tabela IV - Índice de consistência e teor de água das argamassas.

[Table IV - Consistency index and water content of the mortars.]

\begin{tabular}{ccc}
\hline Argamassa/Traço & $\begin{array}{c}\text { Teor de água } \\
(\%)\end{array}$ & $\begin{array}{c}\text { Consistência } \\
(\mathrm{mm})\end{array}$ \\
\hline Areia natural/1:3:0,56 & 14 & 245 \\
Resíduo de EFS/1:3:0,52 & 13 & 260 \\
\hline
\end{tabular}


por resíduo de escória de fluxo de soldagem praticamente não afetou a trabalhabilidade das argamassas, pois essa propriedade é diretamente relacionada com a consistência.

A Tabela V apresenta os resultados da densidade de massa no estado fresco e teor de ar incorporado das argamassas. Verifica-se que a argamassa incorporada com resíduo de escória de fluxo de soldagem apresenta maior densidade de massa fresca e menor teor de ar incorporado. Isto é coerente e torna a argamassa mais compacta. Além disso, as argamassas de múltiplo uso estudadas podem ser classificadas de acordo com a NBR 13281 [31] como sendo

Tabela V - Densidade no estado fresco e teor de ar incorporado das argamassas.

[Table V-Fresh state density and incorporated air content of the mortars.]

\begin{tabular}{cccc}
\hline $\begin{array}{c}\text { Argamassa/ } \\
\text { Traço }\end{array}$ & $\begin{array}{c}\text { Densidade } \\
\text { no estado } \\
\text { fresco }\left(\mathrm{g} / \mathrm{cm}^{3}\right)\end{array}$ & $\begin{array}{c}\text { Teor de ar } \\
\text { incorporado } \\
(\%)\end{array}$ & $\begin{array}{c}\text { NBR } \\
13281\end{array}$ \\
\hline $\begin{array}{c}\text { Areia natural/ } \\
\text { 1:3:0,56 }\end{array}$ & 2,02 & 10 & Tipo b \\
$\begin{array}{c}\text { Resíduo de EFS/ } \\
\text { 1:3:0,52 }\end{array}$ & 2,41 & 8 & Tipo b \\
\hline
\end{tabular}

do tipo $\mathbf{b}$ (teor de ar incorporado entre 8 e 18\%).

Na Fig. 5 estão apresentados os resultados de resistência à compressão das argamassas estudadas. As argamassas atingiram resistência mecânica superior ao valor exigido pela norma NBR 13281 [31], que é de $\geq 8 \mathrm{MPa}$ (classe III). Notase que a resistência á compressão aumenta com o aumento do tempo de cura. A argamassa incorporada com resíduo de escória de fluxo de soldagem $(1: 3: 0,52)$ apresentou maior resistência mecânica, principalmente para os maiores tempos de cura, onde alcançou $36 \mathrm{MPa}$ para 28 dias e $42 \mathrm{MPa}$ para 120 dias. Este resultadoé importante devido à argamassa preparada

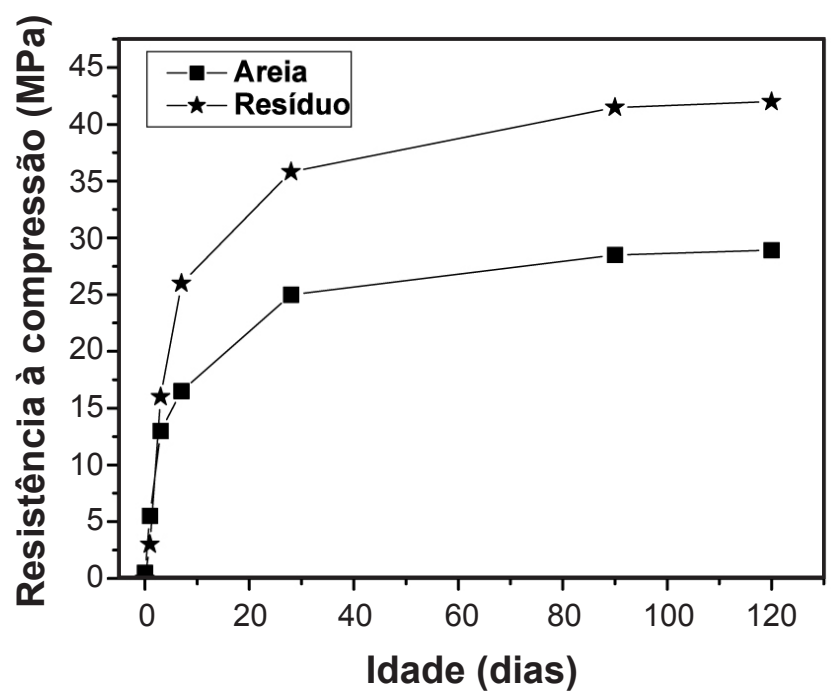

Figura 5: Resistência à compressão das argamassas. [Figure 5: Compressive strength of the prepared mortars.] com resíduo de escória de fluxo de soldagem, como agregado miúdo em substituição total da areia natural, apresentar um desempenho mecânico em cerca de $30 \%$ superior.

Na Fig. 6 estão apresentados os resultados de retração linear dos corpos cerâmicos queimados. A retração linear constitui-se numa importante propriedade física usada para determinar e controlar as dimensões do produto cerâmico final, além de estar relacionada ao grau de sinterização do material. Pode-se observar que a incorporação do resíduo de escória de fluxo de soldagem resultou no aumento dos valores de retração linear das peças cerâmicas. Isto possivelmente está relacionado à composição químico-mineralógica do resíduo, que contribuiu para a maior sinterabilidade das peças cerâmicas. Os valores de retração linear obtidos $(1,17-2,46 \%)$ estão compreendidos na faixa apropriada para fabricação de produtos de cerâmica vermelha para construção civil [30]. Este resultado indica que as peças cerâmicas queimadas entre 850 e $950{ }^{\circ} \mathrm{C}$ apresentaram boa estabilidade dimensional. $\mathrm{O}$ efeito da temperatura de queima foi o de aumentar a retração linear, que contribuiu para maior densificação das peças cerâmicas.

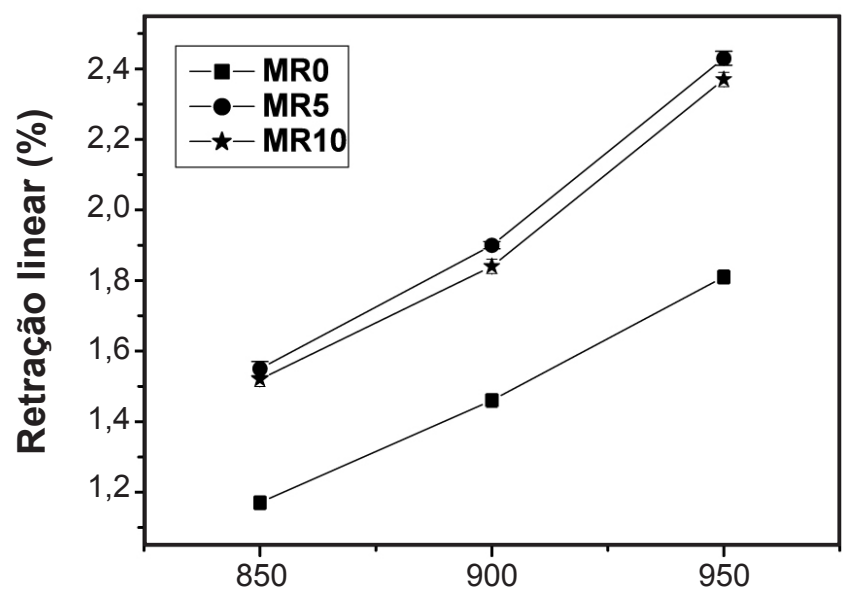

Temperatura de queima $\left({ }^{\circ} \mathrm{C}\right)$

Figura 6: Retração linear das peças cerâmicas queimadas. [Figure 6: Linear shrinkage linear of the fired ceramic pieces.]

Na Fig. 7 estão apresentados os resultados de absorção de água das peças cerâmicas queimadas. Os resultados mostram que, em geral, as peças cerâmicas apresentaram uma tendência de diminuição nos valores de absorção de água (porosidade aberta), principalmente para incorporação acima de $5 \%$. Os resultados mostram ainda que a absorção de água não apresenta grandes alterações com a temperatura de queima empregada $\left(850-950{ }^{\circ} \mathrm{C}\right)$, cujas flutuações estão dentro das dispersões encontradas. Isto é importante devido ao fato de que no Brasil, em geral, as empresas de cerâmica vermelha queimam seus produtos, em particular tijolos maciços e blocos cerâmicos, em temperaturas até $950^{\circ} \mathrm{C}$. Além do mais, os resultados de absorção de água também indicaram que não há restrições quanto à incorporação de até $10 \%$ de resíduo de escória de soldagem na massa cerâmica vermelha de 


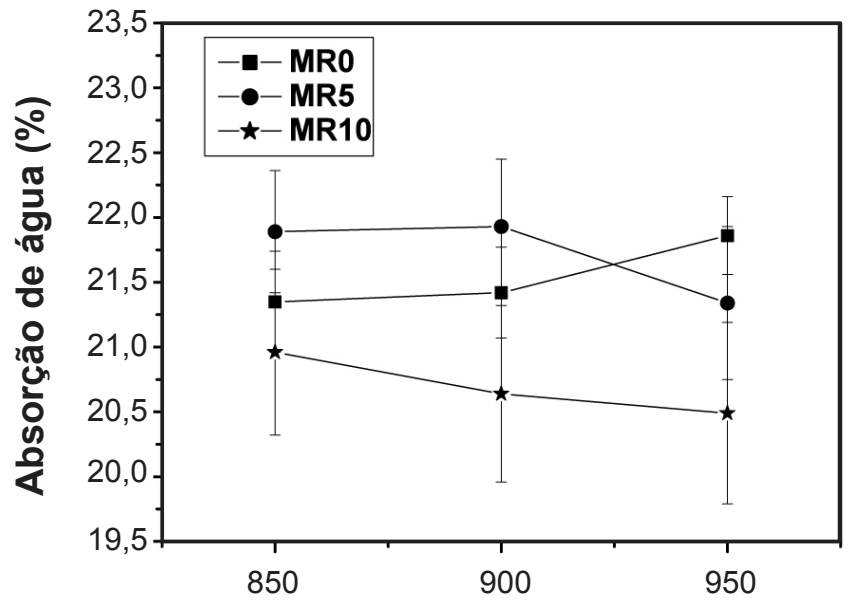

Temperatura de queima $\left({ }^{\circ} \mathrm{C}\right)$

Figura 7: Absorção de água das peças cerâmicas queimadas. [Figure 7: Water absorption of the fired ceramic pieces.]

referência (amostra MR0). O valor especificado de absorção de água para tijolos maciços e blocos cerâmicos $(<25 \%)$ foi atingido já a partir da temperatura queima de $850{ }^{\circ} \mathrm{C}$.

A porosidade aparente das peças cerâmicas é mostrada na Fig. 8. Verifica-se uma tendência de queda nos valores de porosidade aparente, para adições do resíduo acima de 5\%. Isto está de acordo com os resultados de absorção de água. Já a temperatura de queima não provocou grandes alterações na porosidade aparente, para a faixa de temperatura empregada. Além disso, os valores obtidos de porosidade aparente estão dentro da faixa adequada para fabricação de cerâmica vermelha [18]. Os resultados de massa específica aparente das peças cerâmicas são apresentados na Fig. 9. Como esperado, o resíduo de escória de fluxo de soldagem promoveu uma maior densificação das peças cerâmicas. Isto está de acordo com os resultados de absorção de água (Fig. 7) e porosidade aparente (Fig. 8).

A resistência mecânica das peças cerâmicas foi avaliada em termos de tensão de ruptura à flexão (Fig. 10). Os

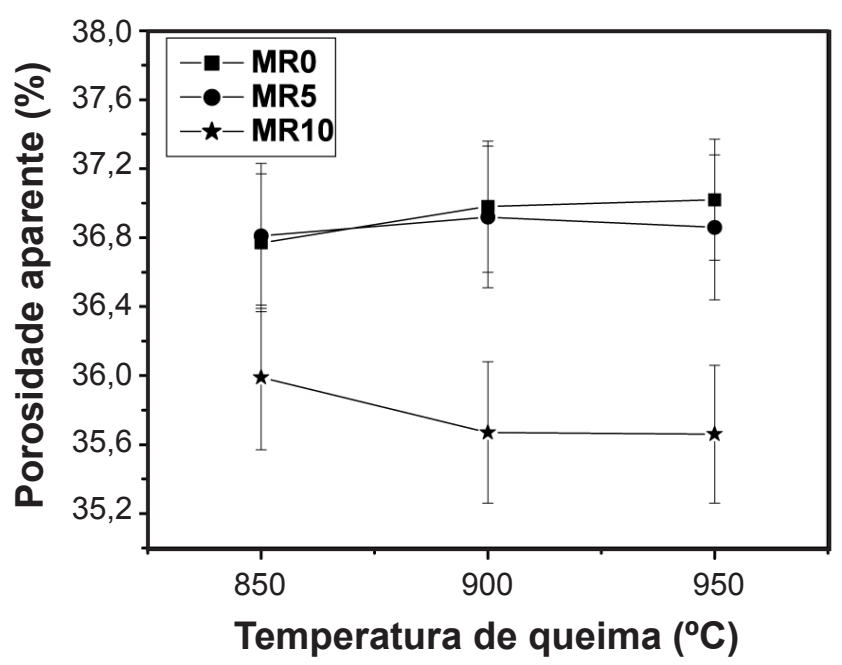

Figura 8: Porosidade aparente das peças cerâmicas queimadas. [Figure 8: Apparent porosity of the fired ceramic pieces.]

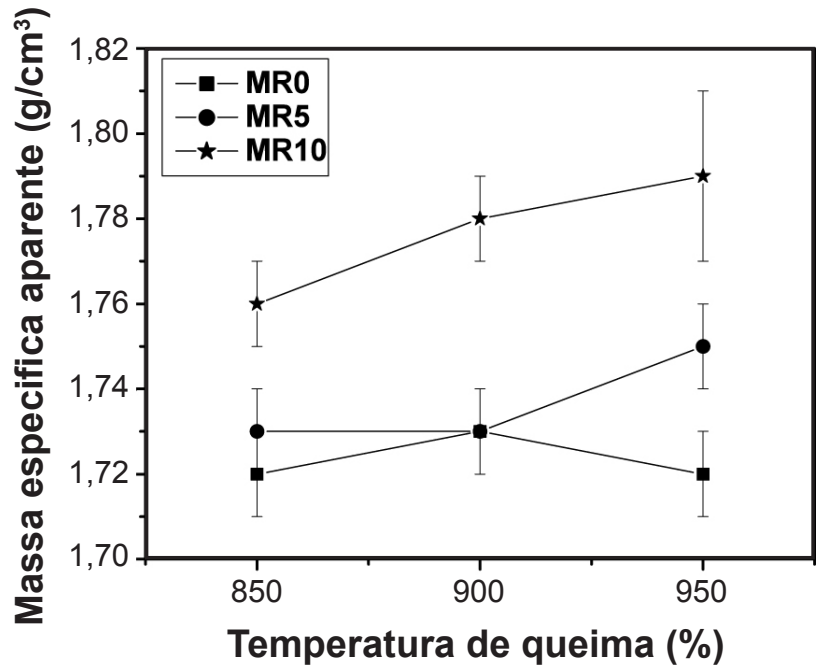

Figura 9: Massa específica aparente das peças cerâmicas queimadas.

[Figure 9: Apparent specific mass of the fired ceramic pieces.]

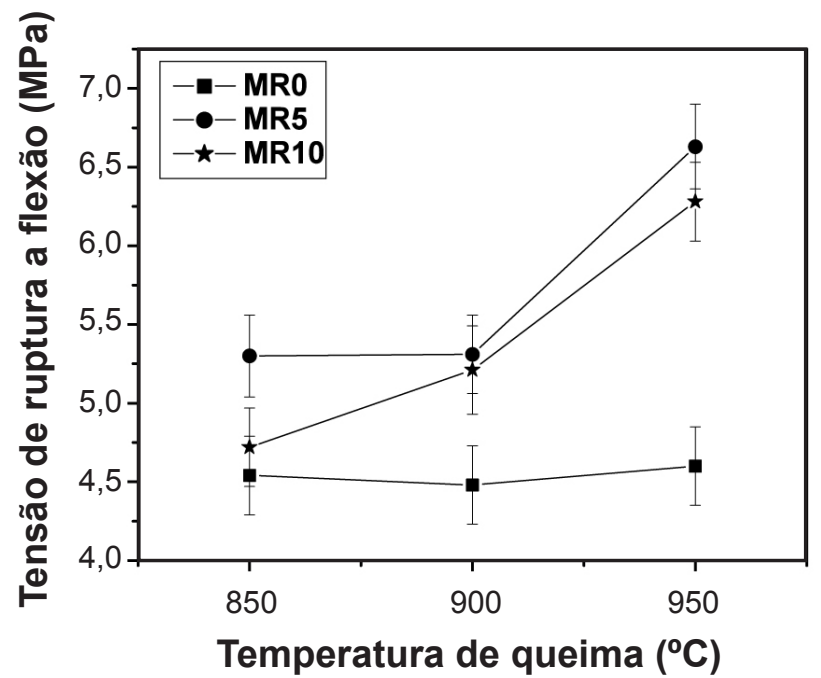

Figura 10: Tensão de ruptura a flexão das peças cerâmicas queimadas.

[Figure 10: Flexural strength of the fired ceramic pieces.]

resultados indicam que incorporação do resíduo de escória de fluxo de soldagem aumentou a resistência mecânica das peças cerâmicas. Isto se deve fundamentalmente ao fechamento parcial da porosidade aberta durante o processo de sinterização, resultando em peças cerâmicas mais densas. De forma que os resultados de resistência mecânica corroboram os demais resultados discutidos anteriormente relacionados à retração linear, absorção de água e massa específica aparente.

Na Fig. 11 pode ser visualizado o efeito da incorporação do resíduo de escória de fluxo de soldagem na coloração das peças de cerâmica vermelha queimadas em $950{ }^{\circ} \mathrm{C}$. Verificase que a adição do resíduo tende a modificar a cor de queima das peças cerâmicas. Em geral tem-se que as peças isentas de resíduo (amostra MR0) apresenta uma cor vermelhoalaranjada típica dos produtos de cerâmica vermelha. Quando 


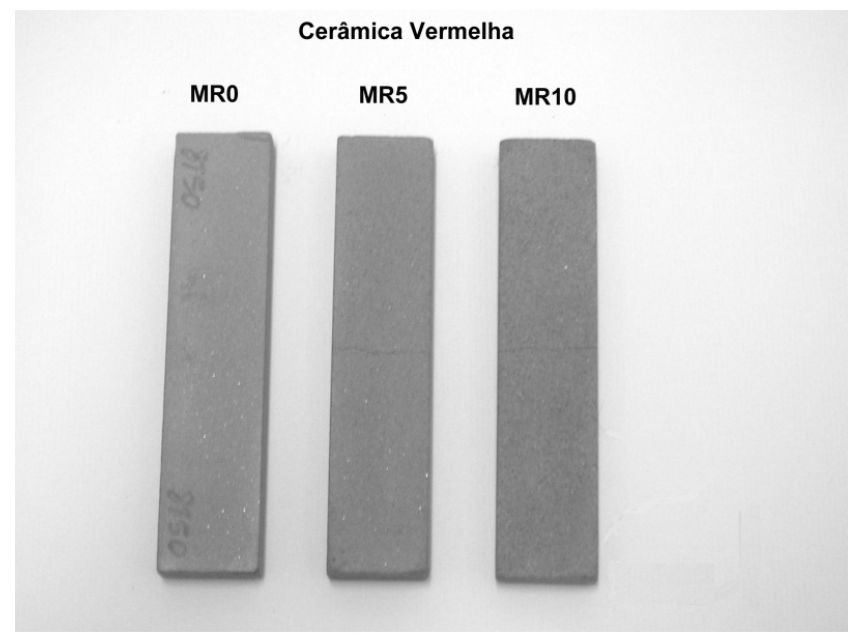

Figura 11: Peças de cerâmica vermelha queimadas em $950^{\circ} \mathrm{C}$. [Figure 11: Red ceramic pieces fired at $950^{\circ} \mathrm{C}$.]

se adiciona o resíduo tem-se uma tendência de escurecimento da coloração, principalmente para o maior teor de resíduo incorporado (amostra MR10). Foi verificado também que as peças de cerâmica vermelha não apresentaram qualquer indicação de manchas superficiais e defeitos de coração negro, como um resultado da incorporação de resíduo de escória de fluxo de soldagem.

\section{CONCLUSÕES}

Os resultados demonstram a possibilidade de uso de resíduo de escória de fluxo de soldagem, gerado por empresas do setor metal-mecânico, como uma matériaprima alternativa de baixo custo para fabricação de produtos cerâmicos para construção civil como argamassa de múltiplo uso e cerâmica vermelha (tijolos maciços e blocos cerâmicos). Estes processos de reciclagem certamente trarão benefícios econômicos e ambientais. A argamassa de múltiplo uso incorporada com resíduo de escória de fluxo de soldagem, quando comparada à argamassa tradicional obtida com areia natural, apresentou melhor comportamento em termos de propriedades físico-mecânicas (consistência, densidade no estado fresco, teor de ar incorporado e resistência mecânica). Os resultados também mostraram que o resíduo de escória de fluxo de soldagem pode ser usado como matéria-prima alternativa em substituição parcial de argila natural na fabricação de cerâmica vermelha.

\section{AGRADECIMENTOS}

Ao $\mathrm{CNPq}$ pelo apoio financeiro e também às empresas Machado Vianna Com. Ind. Ltda. - Caldeiraria, Usinagem e Fundição e Aaborg Industries S.A. pelo fornecimento do resíduo de escória de fluxo de soldagem.

\section{REFERÊNCIAS}

[1] R. P. R. Paranhos, A. C. Souza, Soldagem a arco submerso, SENAI, RJ, CETEC de Solda, Rio de Janeiro, RJ
(1999) 77p.

[2] P. J. Modenesi, Técnica operatória da soldagem SAW, http://www.infosolda.com.br/, acessado em 03/03/08.

[3] M. Dondi, M. Marsigli, B. Fabbri, Tile Brick Int. 13 (1997) 218-225.

[4] R. R. Menezes, G. A. Neves, H. C. Ferreira, Rev. Bras. Eng. Agríc. Amb. 6, 2 (2002) 303-313.

[5] P. A. Bingham, R. J. Hand, Adv. Appl. Ceram. 105, 1 (2006) 21-31.

[6] L. F. R. Miranda, S. M. S. Selmo, Desempenho de revestimentos de argamassas com entulho reciclado, Boletim Técnico, Escola Politécnica da USP, BT/PCC/277, S. Paulo, SP (2001) 12p.

[7] V. Petkova, V. Samichkov, Const. Build. Mater. 21, 6 (2007) 1177-1181.

[8] A. G. Liew, C. H. K. Wong, A. A. Samad, M. J. M. M. Noor, A. M. Baki, Waste Manag. Res. 22, 4 (2004) 226233.

[9] E. M. S. Oliveira, V. G. Sampaio, J. N. F. Holanda, Ind. Ceramics 26, 1 (2006) 71-76.

[10] R. Sarkar, N. Singh, S. K. Das, Waste Manag. Res. 25, 6 (2007) 566-571.

[11] J. Geiseler, Waste Manag. 16, 1-3 (1996) 59-63.

[12] P. M. Giffort, J. E. Gillott, Cem. Concrete Res. 26, 1(1996) 21-26.

[13] L. S. Pioro, I. L. Pioro, Waste Manag. 24, 4 (2004) 371 379.

[14] G. F. Morete, R. P. R. Paranhos, J. N. F. Holanda, Sold. Insp. 11, 3 (2006) 141-146.

[15] H. Badiee, A. Maghsoudipour, B. R. Dehkordi, Adv. Appl. Ceram. 107, 2 (2008) 111-115.

[16] S. M. S. Selmo, Propriedades e especificações de argamassas industrializadas de múltiplo uso, Boletim Técnico, Escola Politécnica da USP, BT/PCC/310, S. Paulo, SP (2002) 27p.

[17] SINDIPEDRAS, Sindicato da Indústria de Mineração de Pedra Britada do Estado de S. Paulo, http://www. sindipedras .org.br, acessado em 03/2006.

[18] P. S. Santos, Ciência e tecnologia de argilas, vol. 1, $2^{\text {a }}$ Ed., Edgard Blücher Ltda., S. Paulo, SP (1989) 408p.

[19] ABNT, Associação Brasileira de Normas Técnicas, NBR 7214: Areia normal para ensaio de cimento - especificações, Rio de Janeiro, RJ (1982).

[20] ABNT, Associação Brasileira de Normas Técnicas, NBR 7251: Agregado em estado sólido - determinação da massa unitária, Rio de Janeiro, RJ (1982).

[21] ABNT, Associação Brasileira de Normas Técnicas, NBR 6508: Grãos de solos que passam na peneira de 4,8 mm - determinação da massa específica, Rio de Janeiro, RJ (1982).

[22] G. P. Souza, S. J. G. Sousa, L. A. H. Terrones, J. N. F. Holanda, Cerâmica 51, 320 (2005) 180-186.

[23] ABNT, Associação Brasileira de Normas Técnicas, NBR 9776: Agregados - determinação de massa específica de agregados miúdos por meio de frasco de Chapman, Rio de Janeiro, RJ (1987).

[24] ABNT, Associação Brasileira de Normas Técnicas, 
NBR 13276: Argamassa para assentamento de paredes e revestimentos de paredes e tetos - determinação do teor de água e para obtenção do índice de consistência-padrão, Rio de Janeiro, RJ (1985).

[25] ABNT, Associação Brasileira de Normas Técnicas, NBR 13278: Argamassa para assentamento de paredes e revestimentos de paredes e tetos - determinação da densidade de massa e do teor de ar incorporado, Rio de Janeiro, RJ (1995).

[26] ABNT, Associação Brasileira de Normas Técnicas, NBR 13279: Argamassa para assentamento de paredes e revestimentos de paredes e tetos - determinação da resistência à compressão, Rio de Janeiro, RJ (1995).

[27] ABNT, Associação Brasileira de Normas Técnicas,
NBR 6459-84, Solo: Determinação do limite de liquidez, Rio de Janeiro (1984).

[28] ABNT, Associação Brasileira de Normas Técnicas, NBR 7180-84, Solo: Determinação do limite de plasticidade, Rio de Janeiro, RJ (1984).

[29] L. Davis, An introduction to welding fluxes for mild and low alloy steels, The Welding Institute, Cambridge, Inglaterra (1981) 34p.

[30] M. Dondi, Int. Ceram. J. (2003) 58.

[31] ABNT, Associação Brasileira de Normas Técnicas, NBR 13281: Argamassa industrializada para assentamento de paredes e revestimentos de paredes e tetos especificação, Rio de Janeiro, RJ (1995).

(Rec.08/04/2009, Rev. 30/04/2009, Ac. 06/06/2009) 